\section{Commentary: Permanent pacemaker implantation after cardiac surgery: Patience for our patients}

\author{
Kimberly A. Holst, MD
}

In this issue of the Journal, Bis and colleagues ${ }^{1}$ report their experience in 145 patients who received permanent pacemakers (PPMs) following cardiac surgery who also had electrophysiologic follow-up. Intrinsic conduction recovered during follow-up in roughly one half of the patients; independent factors associated with not being PPM dependent included pacemaker implantation on or before postoperative day 6 and sinus-node dysfunction.

Surgeons must decide how to approach PPM placement in the postoperative setting to balance the timing of PPM implantation, waiting for the return of intrinsic conduction, and avoiding unnecessary device placement and resulting complications $^{2,3}$ while discharging patients in a timely manner. To this end, the authors recommend PPM implantation on or after postoperative day 7 .

The main limitation of this study is that the entire surgical denominator was not included; the institutional PPM insertion rate was $1.2 \%$, but we do not know the clinical status of the rest of the population and how recovery of intrinsic conduction progressed postoperatively. Complete assessment of the postoperative population would provide insight into progression in clinical status from postoperative days 4 and 5 and how things had changed by postoperative day 6 and 7. Omission of these data may have skewed the analysis. Appreciating that this would be a great undertaking for the authors and not feasible in this manuscript, it is a point of interest for future studies.

Another point of interest would be a time-to-event analysis of freedom from PPM dependence. The authors

\footnotetext{
From the Department of Cardiovascular Surgery, Mayo Clinic, Rochester, Minn Disclosures: Author has nothing to disclose with regard to commercial support. Received for publication Feb 12, 2020; accepted for publication Feb 15, 2020; available ahead of print Feb 21, 2020.

Address for reprints: Kimberly A. Holst, MD, Department of Cardiovascular Surgery, Mayo Clinic, 200 First St SW, Rochester, MN 55905 (E-mail: holst.kimberly1@ mayo.edu).

J Thorac Cardiovasc Surg 2021;162:825

$0022-5223 / \$ 36.00$

Copyright (c) 2020 by The American Association for Thoracic Surgery

https://doi.org/10.1016/j.jtcvs.2020.02.069
}

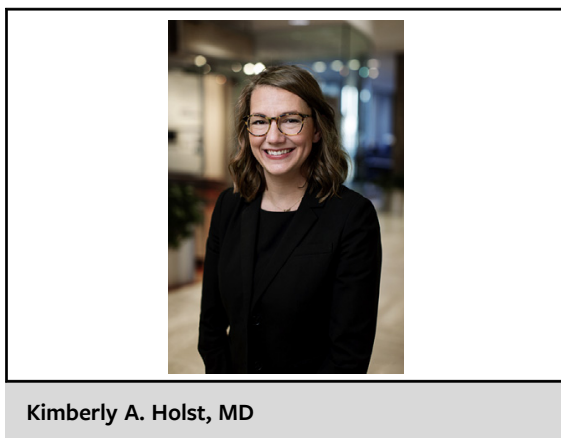

\begin{abstract}
CENTRAL MESSAGE
Patience is a virtue when electing to proceed with PPM implantation postoperatively while continuing to facilitate hospital discharge to minimize impact on hospital length of stay.
\end{abstract}

analyzed freedom from PPM dependence as a dichotomous variable, meaning that return of intrinsic rhythm 2 months postoperatively was treated the same as if intrinsic rhythm returned at 2 years following surgery. This analysis may not impact the early decision to place a PPM but would likely provide insight to late mortality outcomes. ${ }^{4,5}$

Bis and colleagues ${ }^{1}$ should be congratulated on this analysis and this substantial contribution to the literature. Questions regarding impact of valvular surgery and the clinical status leading up to postoperative 7 remain. In the end, patience is a virtue when electing to proceed with PPM implantation while continuing to facilitate hospital discharge to minimize impact on hospital length of stay.

\section{References}

1. Bis J, Gościńska-Bis K, Gołba K, Gocoł R, Zębalski M, Deja MA. Permanent pacemaker implantation after cardiac surgery: optimization of the decision process. J Thorac Cardiovasc Surg. 2021;162:816-24.e3.

2. Poole JE, Gleva MJ, Mela T, Chung MK, Uslan DZ, Borge R, et al. Complication rates associated with pacemaker or implantable cardioverter-defibrillator generator replacements and upgrade procedures: results from the REPLACE registry. Circulation. 2010;122:1553-61.

3. Wiegand UKH, Bode F, Bonnemeier H, Eberhard F, Schlei M, Peters W. Longterm complication rates in ventricular, single lead VDD, and dual chamber pacing. Pacing Clin Electrophysiol. 2003;26:1961-9.

4. Greason KL, Lahr BD, Stulak JM, Cha YM, Rea RF, Schaff HV, et al. Long-term mortality effect of early pacemaker implantation after surgical aortic valve replacement. Ann Thorac Surg. 2017;104:1259-64.

5. Pyatt JR, Somauroo JD, Jackson M, Grayson AD, Osula S, Aggarwal RK, et al Long-term survival after permanent pacemaker implantation: analysis of predictors for increased mortality. Europace. 2002;4:113-9. 